\title{
$\underline{\mathbf{P}-7}$
}

\section{Cytotoxicity Effect and Antioxidant Activity of Malaysian Vatica Pauciflora}

\author{
Aisyah Salihah Kamarozaman ${ }^{1, *}$, Jalifah Latip ${ }^{2}$, Nor Fadilah Rajab ${ }^{3}$, Wan Zuraida Wan Mohd Zain ${ }^{4}$ \\ and Diyana Mazuin Ridzuan ${ }^{3}$ \\ ${ }^{I}$ Centre of Foundation Studies, MARA University of Technology, Puncak Alam Campus, 42300 Bandar Puncak Alam, \\ Selangor, Malaysia, ${ }^{2}$ School of Chemical Sciences and Food Technology, Faculty of Sciences and Technology, National \\ University of Malaysia, 43600 Bangi, Selangor, Malaysia; ${ }^{3}$ School of Diagnostic and Applied Health Sciences, Faculty \\ of Health Sciences, National University of Malaysia, Jalan Raja Muda Abdul Aziz, 50300 Kuala Lumpur, Malaysia; \\ ${ }^{4}$ Faculty of Applied Science, MARA University of Technology, Pahang Campus, 26400 Bandar Tun Abdul Razak, \\ Jengka, Pahang, Malaysia; E-mail: aisyahsalihah@yahoo.co.uk
}

The crude hexane, ethyl acetate, methanol and ethanol extracts of the woods and twigs of Vatica pauciflora have been examined for their cytotoxicity effect against normal Chang liver cells. None of these extracts found to be toxic to normal Chang liver cells, instead the crude extracts of the twigs had increased the cell proliferation to two-fold. These preliminary results indicated the extracts of the woods and twigs of $V$. pauciflora exhibited hepatoprotective effect in vitro. The crude extracts of the twigs also exhibited significant antioxidative properties when evaluated using the Ferric Reducing Antioxidant Power (FRAP) and radical scavenging assays, Total Phenolic Content (TPC), Ferric thiocyanate (FTC) as well as Thiobarbituric acid (TBA) methods. However, further investigation has to be made at molecular level to prove the safety usage of this plant in traditional medicinal preparation.

Keywords: Vatica pauciflora, hepatoprotective, proliferation, antioxidative. 